\title{
DAMASCIO Y EL CIERRE DE LA ESCUELA NEOPLATÓNICA DE ATENAS
}

\author{
José M. Zamora \\ Universidad Autónoma de Madrid
}

\section{RESUMEN}

En 529, Justiniano, temeroso de ver amenazada la unidad del Imperio cristiano, ordena el cierre de la escuela neoplatónica recientemente restaurada por Damascio, y mitigar así el último foco de enseñanza pagana. El último diádoco y sus discípulos se exilian a Persia, donde el régimen político del rey Cosroes les garantizaba la libertad de conciencia. Sin embargo, pronto decepcionados por una realidad política muy diferente, los filósofos regresaron a su patria de origen o se dispersaron en el Imperio Bizantino.

Palabras clave: Damascio, Simplicio, Escuela neoplatónica de Atenas, Agatías, Justiniano.

\begin{abstract}
In 529, Justinian, seeing the unity of the Christian Empire threatened, orders the closing of Athens'Neoplatonic School, which had recently been restored by Damascius. The last diadochus and their followers go then to exile in Persia, where the political regime of King Chosroes guarantees them liberty of conscience. However, soon disappointed by a political reality very different from the one they had expected to find, some of them go back to their homeland, while some others scatter all over the Byzantine Empire.
\end{abstract}

Key words: Damascius, Simplicius, Athens'Neoplatonic School, Agathias, Justinian.

Damascio cierra el período de incertidumbre que había marcado la enseñanza de la filosofía tras la muerte de Proclo (485 d.C). El último sucesor (diádoco) se hallaba al frente de la escuela neoplatónica de Atenas en el momento que fue clausurada por orden del emperador Justiniano en 529 d.C. El neoplatonismo pagano sobrevivirá aún al borde del desierto, en Siria, patria de Damascio, con Nísibis, Edesa y Harrân, y en Persia, con Yundisapûr, lugares donde se transmite a los primeros metafísicos del islam, que llevarán la palabra de Mahoma de la religión a la filosofía. Por este trasvase crucial, el final del neoplatonismo helénico coincide con el surgimiento de una filosofía prodigiosa que, de Persia a España, se gesta a la sombra del helenismo'.

1 Como ha destacado J. Lomba, la mezcla de Aristóteles con el neoplatonismo dio como resultado las filosofías de al-Kindî, al-Fârâbî y Avicena. Tras ellas, Aristóteles será desterrado y el pensamiento continúa por la línea mística de Suhrawardî. En al-Andalus, Aristóteles también entra unido al neoplatonismo y a elementos místicos. El neoplatonismo se halla presente también en la mística sûfí andalusí, desde Ibn Masarra hasta Ibn’Arabî de Murcia. $\mathrm{El}$ aristotelismo de Avempace aparece mezclado de neoplatonismo, y no llega a realizar una interpretación totalmente depurada de todas las adherencias neoplatónicas, como lo hará Averroes. Cfr. J. Lomba: «El pensamiento islámico occidental», en M. Cruz Hernández (ed.): Filosofias no occidentales, Madrid, 1999, p. 240. 
Después de la muerte de Proclo, la escuela neoplatónica de Atenas se sume en una profunda crisis, debido fundamentalmente a la confluencia de dificultades externas (la expansión del cristianismo) con dos inconvenientes internos (la enfermedad del diádoco Marino y el interés de Hegias centrado más en la teúrgia que en la filosofía) ${ }^{2}$. En la Vida de Isidoro $^{3}$, Damascio compone una biografía de su maestro y una «historia filosófica» general del neoplatonismo desde finales del s. IV al s. V. d.C. La obra, escrita bajo el reinado de Teodorico en Italia (en torno a 497-526), constituye un manifiesto apologético que pretende frenar precisamente el triunfo del cristianismo y la penetración de la teúrgia. En su biografía, Damascio programa una restauración de la Academia platónica, para lo que propone una reconstrucción del cursus neoplatónico: lectura ordenada de Aristóteles (estudio del mundo sensible, de la lógica y de los principios), de Platón (estudio del mundo de las formas inteligibles, de la dialéctica y de la teología) y de los Oráculos caldeos (estudio de la teúrgia) ${ }^{4}$. En este trabajo nos interesa analizar las causas que producen el cierre de la escuela neoplatónica de Atenas, y si existe o no una conexión directa de su clausura con el exilio a Persia de Damascio y sus seguidores.

\section{DAMASCIO: EL ÚLTIMO DIÁDOCO DE LA ESCUELA NEOPLATÓNICA DE ATENAS}

Damascio es el artífice de la restauración de la filosofía en Atenas. Pero, ¿quién era este representante postrero del paganismo? No disponemos de muchos datos sobre su vida. La entrada de la Suda (s. X) lo define así: «Damascio, filósofo estoico, originario de Siria, compañero de Simplicio y Eulalio, originarios de Frigia. Alcanzó su madurez en tiempos de Justiniano y escribió comentarios a Platón, un Tratado de los Principios y una Historia filosófica» ${ }^{5}$. El texto de la Suda califica a Damascio de «filósofo estoico», la explicación puede deberse a una confusión del maestro con su discípulo Simplicio, autor de un Comentario al Manual de Epicteto. El propio Simplicio describe a su maestro en su Comentario a la Física como: «un hombre apasionado por la investigación, que ha introducido en filosofía numerosos trabajos agotadores» ${ }^{6}$.

Damascio nace en Damasco (Siria) ${ }^{7}$, entre los años 460 y 462 . Muy joven se instala en Alejandría, donde se dedica al estudio de la retórica, bajo la dirección de Teón ${ }^{8}$, a la interpretación

2 Sobre la decadencia de la escuela neoplatónica de Atenas, tras la desaparición de Proclo, cf. Focio: Biblioteca, codex, 242, Damascio: Vida de Isidoro (Vit. Isid.), 221, 227 y 23 d. Cf. Ph. Hoffmann: «Damascius», en R. Goulet (ed.): Dictionnaire des philosophes antiques II. De Babéyca d'Argos à Dyscolios (DPhAn. II), París, 1994, p. 555.

3 Obra conservada en la Biblioteca de Focio (códices n ${ }^{\circ} 181$ y 242 ), y por la $S u d a$ (s. X). Las ediciones actuales: C. Zintzen: Damascii Vitae Isidori reliquiae, Hildesheim, 1967; y la reciente traducción y comentario de P. Athanassiadi: Damascius. The Philosophical History. Text with translation and notes, Atenas, 1999. En español, véase el estudio de E. Gutiérrez Lerma, La Vida de Isidoro por Damascio, Tesis doctoral. U.A.M., 1995.

4 Cfr. A.J. Festugière: «L'ordre de lecture des dialogues de Platon aux Ve/VIe siècles», Museum Helveticum, 26, 1969, pp. 282-296 (=reimpreso en Études de philosophie grecque, París, 1971, pp. 535-558); y M.O. GouletCazé: «L'arrière-plan scolaire de l'enseignement dans les écoles néoplatoniciennes», en L. Brisson et alii (eds.): Porphyre. La Vie de Plotin, t. I, París, 1982, pp. 277-286.

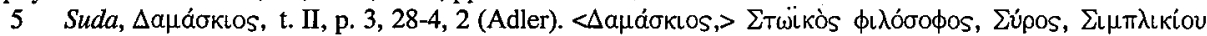

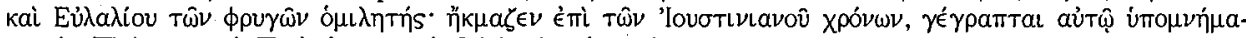

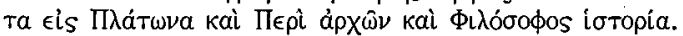

6 Simplicio: Comentario a la Física de Aristóteles (In Phys.), «Corolarium de loco», Commentaria in Aristotelem Graeca (CAG), IX-X, Berlín, 1882-1895, p. 624, 38-625, 1 (Diels).

7 Cfr. Simplicio: In Phys., p. 624, 38 (Diels); Focio: Codex, 181, 125b30, t. II, p. 189 (Henry); Vit. Isid., 200, Focio: Codex, 242, t. VI, p. 43 (Henry).

8 Damascio comenzó su formación con el estudio de la retórica en Alejandría, en la escuela de Teón, durante

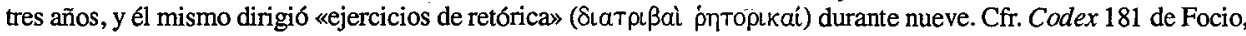
126b40-127a14, t. II, p. 192 (Henry). Damascio explícitamente hace de la retórica una parte de la formación legal. San Agustín, por ejemplo, fue un estudiante que recibió una formación retórica en Cartago, antes de dirigirse a Roma para estudiar leyes (Confesiones, VI, 11-13). 
de Platón y Ptolomeo, con Ammonio, y a la dialéctica, con Isidoro. Durante sus años de formación, la escuela de Alejandría atraviesa los momentos más sombríos. El patriarca monofisita de Alejandría emprende una serie de medidas contra profesores y alumnos paganos. Durante una operación policial, Juliano, el hermano menor de Damascio, fue azotado, según la costumbre egipcia, y pasó la prueba sin lamentarse, dando muestra de una entereza admirable?

La «escuela» neoplatónica de Atenas constituye, en realidad, una comunidad filosófica pri-

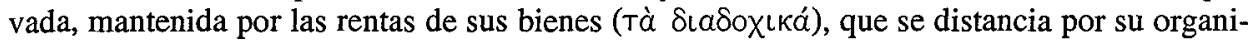
zación institucional y económica de la Antigua Academia fundada por Platón ${ }^{10}$. Asimismo, como demuestran los estudios arqueológicos llevados a cabo por la American School of Classical Studies at Athens ${ }^{11}$, la escuela de Damascio se sitúa a los pies de la Acrópolis, aunque no podamos determinar con precisión su localización, ya que carecemos de testimonios epigráficos.

Muy probablemente, Damascio enseñó al sur de la Acrópolis, en la casa que antes ocuparon Plutarco, Siriano y Proclo, o en alguna de las casas situadas en una de las laderas próximas al Areópago, pero no podemos precisar su ubicación exacta. Para los neoplatónicos el lugar de residencia y enseñanza encerraba un enorme valor simbólico. Marino nos describe la casa de Proclo situada en la proximidades de la Acrópolis y del Partenón, santuario de la «diosa filósofa» Atenea. «En efecto, entre las demás bonanzas, tuvo esta morada muy apropiada para él, en la que habitaban su padre Siriano y su abuelo Plutarco, según lo llamaba él, vecina del templo de Asclepio, célebre por Sófocles, y del de Dioniso, junto al teatro, vista o de otro modo perceptible desde la acrópolis de Atenea» ${ }^{12}$. En el s. IV se imparte sin interrupción la filosofía platónica en Atenas. Sin embargo, la corriente neoplatónica, que parte de las enseñanzas de Plotino, no logra instalarse completamente en Atenas hasta Plutarco, seguidor de Jámblico, quien introduce el neoplatonismo en esta ciudad a finales del s. IV y comienzos del s. V. Antes de llegar a la ciudad de Atenea, la filosofía de Platón recorre Roma, Siria y Asia Menor. Con la llegada a Atenas, los filósofos neoplatónicos de fines de la Antiguiedad pretenden regresar al sentido auténtico del platonismo, instalándose en su lugar de origen.

De un modo general, los neoplatónicos forman parte de las altas esferas de la sociedad. En Atenas, los profesores y los alumnos de la escuela neoplatónica se integran en las clases superiores donde el paganismo continúa vivo, como prueban, por ejemplo, las casas del Areópago, que podrían haberse destinado, además de residencia, a lugares donde se impartiera la filosofía y la retórica ${ }^{13}$.

El manuscrito más antiguo del Tratado de los primeros principios y del Comentario al Parménides, Marcianus graecus 246 (s. IX), nos indica que Damascio llega a ser «diádoco» de la escuela de Atenas, quizás como sucesor de Zenódoto o de Isidoro ${ }^{14}$. Sin embargo, el tér-

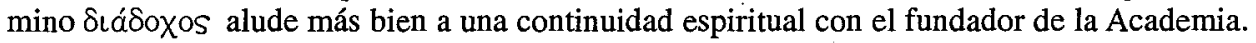
La «escuela» neoplatónica mantiene un cierto «aire de familia» con la Academia de Platón, pero, en la época de Damascio, está radicada en un lugar diferente, a los pies de la Acrópolis,

9 Ver Vit. Isid., 185. Focio, p. 254, 1-3 (Zintzen); t. VI, p. 40 (Henry).

10 Cf. J. Glucker: Antiochus and the Late Academy, Göttingen, 1978, pp. 248-255 y 322-329.

11 Cf. A. Frantz: The Athenian Agora. Results of excavations conducted by the American School of Classical Studies at Athens, vol. XXIV: Late Antiquity: A.D. 267-700, with contributions by H.A. Thompson and J. Travlos, Princeton, 1988, pp. 37-48 y 84-92.

12 Marino de Neápolis: Vida de Proclo, 29, 727-733 (Masullo). Trad. española de J.M. Álvarez Hoz y J.M. García Ruiz: Proclo o de la felicidad, Irún, 1999, p. 39.

13 Cfr. A. Frantz: op. cit., pp. 37-38.

14 Cfr. Damascii Dubitationes et Solutiones. De primis principiiis In Parmenidem, ed. C.E. Ruelle, 2 vols., París, 1889 (=reimpresión, Bruselas, 1965, Amsterdam, 1966); y Damascius. Traité des premiers principes, 3 vols.: I, De l'ineffable et de l'un; II, De la traide et de l'unifié; III, De la procession et de l'unifié, ed. L.G. Westerink y J Combès, París, 1986-1991. Damacius. Commentaire du Parménide de Platon, 2 vols., ed. LG. Westerink y J. Combès, avec la collaboration de A.Ph. Segonds, París, 1997-2002. 
y gestionada a partir de una fortuna privada. Así pues, Damascio representa el último eslabón de una «cadena de oro» ${ }^{15}$ que vincula a los últimos neoplatónicos con el propio Platón, pero no geográfica ni institucionalmente, sino en tanto herederos espirituales de una tradición que preserva una verdad revelada por los dioses ${ }^{16}$.

\section{LA ORDEN DE JUSTINIANO: 529 D.C.}

Damascio reorganiza la escuela neoplatónica de Atenas a contracorriente del poder establecido. Una de las principales medidas que adopta Justiniano, para impedir la expansión de los focos anticristianos, fue la prohibición de la paideia pagana. El objetivo fundamental del emperador es consolidar la unidad religiosa del Imperio. Las disposiciones contra los herejes, los judíos y los paganos les excluye del servicio militar, de los puestos públicos y de la enseñanza. Así, en 529 d.C. tiene lugar la clausura de la escuela de Atenas ${ }^{17}$. En ese momento, Damascio se halla al frente de la escuela como díadoco.

La disposición I, 5, 18, 4 del Codex Iustinianus (Cod. Iust.) obliga a los paganos a instruirse en la religión cristiana bajo pena de confiscación de todas sus posesiones. De igual modo, en Cod. Iust., I, 5, 12 se prohíbe a los paganos que profesan las antiguas prácticas y creencias, y a sus hijos, acceder a puestos públicos, obligándolos a aprender los fundamentos de la fe cristiana. Pero la disposición principal aparece en Cod. Iust., I, 11, 10:

Omnem autem doctrinam ab iis, qui impiorum paganorum furore laborant, doceri prohibemus, ut ne hoc modo simulent, se eos, qui misera sorte ad ipsos veniant, erudire, sed severa animos erudiendorum corrumpant, neque magis aliquid annonae ex publico percipiant, non habentes licentiam, ne ex divinis quidem rescriptis vel pragmaticis sanctionibus eiusmodi ius sibi vindicandi $[\ldots]^{18}$.

Podemos poner en conexión este párrafo de la ley con la clausura de la escuela de Atenas, decretada por Justiniano en el año 529 d.C. Aparte de los textos jurídicos del Cod. Iust., la única fuente que nos informa de este hecho es la transmitida por el cronista bizantino Juan Malalas

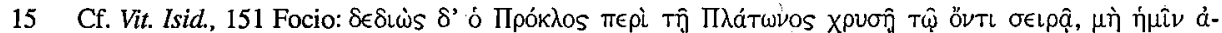

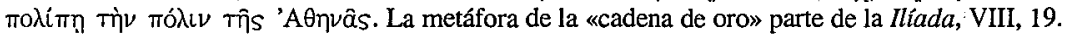

16 Cf. J. Glucker: op. cit., pp. 312-313.

17 Sobre este punto, véanse P. Tannery: «Sur la période finale de la philosophie grecque», Revue philosophique, 42, 1896, pp. 266-287 (reimpresión en J.L. Heiberg (ed.): Mémoires scientifiques, VII [1880-1904], ToulouseParis, 1925, pp. 211-241); A. Cameron: «The end of the Ancient Universities», Caltiers d'Histoire Mondiale, 10, 1967, pp. 653-673; y «The last days of the Academy of Athens», Proceedings of the Cambridge Philological Society, 195, 1969, pp. 7-29, y «La fin de l'Académie», en AA. VV.: Le Néoplatonisme, (Royaumont, 9-13 juin 1969), París, 1971, pp. 281-290. Lermerle: Le premier humanisme byzantin, París, 1971, pp. 68-73; H. Blumenthal: «529 and after: what happened to the Academy?», Byzantion, 48, 1978, pp. 369-385; G. Fernández: «Justiniano y la clausura de la escuela de Atenas», Erytheia, II.2., 1985, pp. 24-30; «El rey persa Khusro I Anosharvan y la filosofía ateniense ante la crisis del año 529 d.C. Un nuevo episodio de la penetración de la cultura griega en Irán», Gerión, 5 , 1987, pp. 171-181; y «La escuela filosófica de Alejandría ante la crisis del año 529», Erytheia, 8.2, 1987, pp. 203207; F. Frantz: op. cit., pp. 84-92; O. Bucci: «La politica culturale di Cosroe Anursivan (521-579), la chiusura delle scuole di Atene (529) e l'esilio degli ultime Maestri pagani in Persia», Studi Biscardi, 6, 1987, pp. 507-552; L.G. Westerink, J. Trouillard \& A.Ph. Segonds (eds.): Prolégomènes à la philosophie de Platon, París, 1990, p. xx; Ph. Hoffmann: art. cit., pp. 556-559; y G. Hällström: «The closing of the Neoplatonic School in A.D. 529: an additional aspect», en P. Caastren (ed.): Post-Herulian Athens. Aspects of life and culture in Athens A.D. 267-529, Helsinki, 1994, pp. 141-160.

18 Codex Iustinianus (Cod. Iust.), I, 11. 10. Corpus Iuris Civilis, I: Institutiones et Digesta, P. Krüger y Th. Mommsen [1872], Berlín, 197322. Traducción castellana de D. Idelfonso L. García del Corral: Cuerpo del Derecho Civil Romano a doble texto, traducido al castellano del latino, Barcelona, 1889-1898. (Edición facsímil, Valladolid, 1988); y F. Hernández-Tejero: Las Instituciones de Justiniano, Madrid, 1961. 
en su Chronographia ${ }^{19}$, redactada en el último tercio del s. VI. Durante el consulado de Fla-

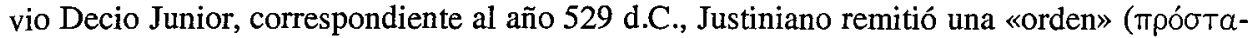

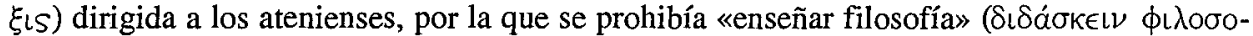

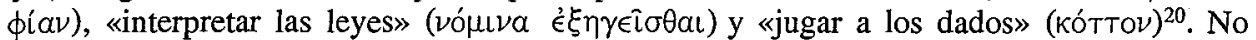
encontramos en la historiografía bizantina ni en los tratados de jurisprudencia ningún texto paralelo que condene simultáneamente la enseñanza de la filosofía, la jurisprudencia y el juego.

La interdicción de la enseñanza de la jurisprudencia podemos ponerla en conexión, además de con la citada prohibición del Cod. Iust., I, 11, 10, 2, que excluía a los paganos de la docencia, con un prefacio del Digesto en que se ordena el cierre de todas las escuelas de derecho, con la excepción de las situadas en Constantinopla, Roma y Beirut ${ }^{21}$. El texto de Malalas parece confirmar la existencia de una escuela de jurisprudencia en Atenas. Con su clausura, apunta G. Fernández, el emperador pretendía «reunir en un único cuerpo, sin confundirlos ni mezclarlos, los 'iura' y las 'leges', la obra de los jurisconsultos clásicos y el material legislativo de sus antecesores ${ }^{22}$. Sin embargo, E. Jeffreys señala una variante hallada en la Crónica del Vaticanus gr. 163, f. $26^{v}$, que indica una prohibición de la «astrología» (áotpovouía ) y no de las «leyes» $(\nu o ́ \mu t \nu a)^{23}$.

La prohibición de los juegos de dados o de cotos (tesserarum sive cottorum ludus) obedece fundamentalmente a factores de índole socio-económica, los juegos de azar, especialmente los de dados, ocasionaban ganancias o pérdidas cuantiosas; y de carácter religioso, durante el juego se pronunciaban con frecuencia blasfemias ${ }^{24}$, como lo ejemplifica un hecho sucedido en Constantinopla que relata el final del pasaje transmitido por Malalas ${ }^{25}$.

Pero detengámonos en la prohibición que aquí nos ocupa, la de «enseñar filosofía». Frente a la tesis de E. Zeller-R. Mondolfo que considera la clausura de la escuela neoplatónica como el golpe que pone fin a una escuela agonizante ${ }^{26}$, Alan Cameron reivindica la vitalidad de la escuela dirigida por Damascio ${ }^{27}$. Por su parte, K. Krumbacher apunta a la carencia de recursos económicos como la causa principal del cierre de la escuela ${ }^{28}$.

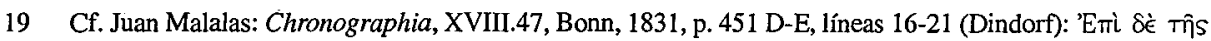

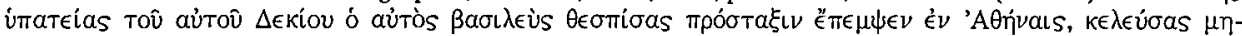

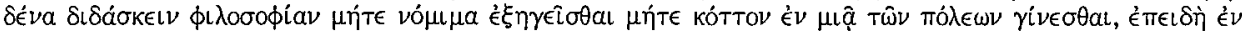

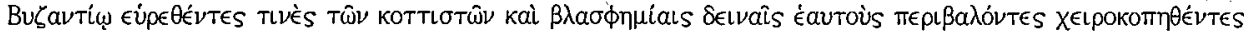

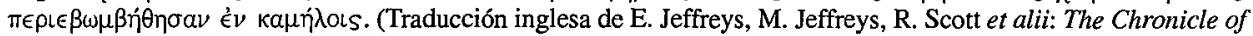
John Malalas, Melbourne, 1986, p. 264).

20 En este pasaje de la Chronographia de Juan Malalas, así como en Cod. Just. I, 4, 25, кóтtos equivale a кúßos, (H.G. Liddell, R. Scott y H. Jones (eds.): A Greek-English Lexicon. (With a revised supplement), Oxford, $1940^{9}$, n.e., 1996, p. 986). El diccionario de G.W.H. Lampe: A patristic Greek Lexicon, Oxford, 1961, define kóTTOS como «dicing», p. 772.

21 Cf. Digesta, vol. I, p. 7 (Krüger).

22 G. Fernández: «Justiniano y la clausura..»., p. 25.

23 Cf. E. Jeffreys: «The transmission of Malalas' Chronicle. 1. Malalas in Greek», en E. Jeffreys, B. Croke y R. Scott (eds.): Studies in John Malalas, Sydney, 1990, p. 264.

24 Cf. Cod. Iust., 3, 43, 1: «...consequenter autem ex hac inordinatione blasphemare Deum conantur». Sobre las leyes justinianeas que prohibían los juegos de dados o de cotos (tesserarum sive cottorum ludus (cfr. 1, 4, 25) y la interdicción de jugar o de presenciar los juegos tanto en casas privadas como en lugares públicos (cfr. 3, 43, 1). Sobre estas prohibiciones, véase el estudio de R. González Fernández: Las estructuras ideologicas del Código de Justiniano, Murcia, 1997, pp. 118-119.

25 Ver supra, n. 19.

26 Cfr. E. Zeller-R. Mondolfo: La filosofia dei Greci nel suo sviluppo storico, Parte terza, vol. VI a cura di G. Martano, Florencia, 1961, pp. 226-228.

27 Cfr. A. Camaron: «The last days..»., pp. 25-29; y «La fin de l'Académie..»., pp. 286-290.

28 Cfr. K. Krumbacher: Geschichte der byzantinischen Literatur von Justinian bis zum Ende des oströmischen Reiches (527-1453) [1897], Nueva York, 1958, vol. 1, pp. 20-22. 


\section{EL TESTIMONIO DE AGATÍAS SOBRE EL EXILIO PERSA}

El escritor bizantino Agatías nos aporta el único testimonio conservado sobre el exilio persa de siete filósofos ${ }^{29}$, después del cierre de las escuelas paganas neoplatónicas decretado por Justiniano.

Poco tiempo antes [con anterioridad a la llegada del embajador Areobindo y del filósofo Uranio junto a Cosroes], Damascio el sirio, Simplicio el cilicio, Eulamio [o Eulalio] el frigio, Prisciano el lidio, Hermias y Diógenes, ambos de Fenicia, Isidoro de Gaza, todos ellos la flor más noble, hablando en términos poéticos, de los filósofos de nuestro tiempo, al no estar satisfechos de la opinión predominante entre los romanos en lo concerniente a lo divino, pensaron que el régimen político de los persas era mucho mejor ${ }^{30}$.

El número de exiliados, según este pasaje de Agatías, coincide con el número de planetas y de sabios en la Grecia antigua, lo que nos hace sospechar, como sugiere Ph. Hoffmann ${ }^{31}$, que no sea fruto del azar, sino que presente estilizado un texto difícil de interpretar. Agatías no nos dice de qué ciudad del Imperio Bizantino provenían los filósofos neoplatónicos, ni tampoco sabemos por su testimonio si habían vivido juntos antes de exiliarse a la corte del rey persa Cosroes. Podemos pensar que, muy probablemente, pero manteniendo siempre nuestra falta de certeza, el último diádoco de la escuela neoplatónica y sus acompañantes procedieran todos de Atenas $^{32}$.

Los siete sabios griegos, «la flor más noble» (Tò ăkpov åwTov) ${ }^{33}$ de los filósofos, no se ven atraídos por la reputación de Cosroes, sino por las costumbres de los persas, insatisfechos por la opinión predominante entre los romanos con respecto a lo divino. Desde la Ciropedia de Jenofonte hasta Damascio podemos apreciar una tradición de «simpatía» de los griegos hacia los persas. Según nos transmite Porfirio en la biografía que dedica a su maestro, Plotino se unió a la comitiva del emperador Gordiano III camino de Persia, con el deseo «de experimentar la filosofía que se practica entre los persas y la que florece entre los indios» ${ }^{34}$. Los griegos consideraban como filosofía el mazdeísmo zoroástrico, la religión oficial de los sasánidas. Como culminación de la formación recibida de Amonio, Plotino busca en los persas no un conjunto de doctrinas, sino un método experimental y práctico, que le permitiera liberarse del cuerpo y sus pasiones. Sin embargo, la muerte de Gordiano en Mesopotamia le impide culminar su proyecto, viéndose obligado a buscar refugio en Antioquía. Una vez que Filipo, el nuevo emperador, firma la paz con los persas, Plotino se traslada a Roma en la primavera de $244^{35}$.

En el pasaje sobre el exilio de Damascio y sus seguidores, Agatías distingue a los siete «excelentes y verdaderos filósofos», que emprenden el camino del exilio a Persia, del médico ig-

29 Agatías: Historias (Hist.), II, 28-32. R. Keydell: Agathiae Myrinaei Historiarum libri quinque, II, Berlín, 1967, pp. 77-83. (Traducción inglesa de J.D. Frendo: Agathias. The Histories, II A, Berlín-Nueva York, 1975, pp. 62-67). Sobre Agatías, véase el estudio de Averil Cameron: Agathias, Oxford, 1970.

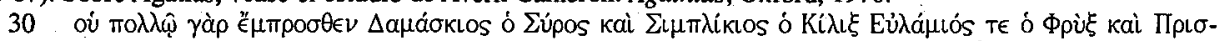

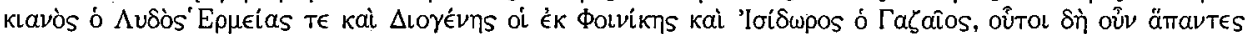

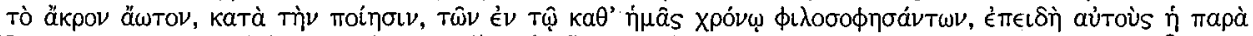

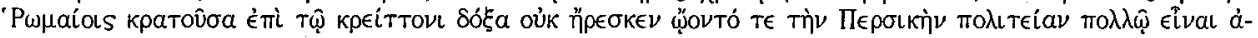
$\mu$ ívova. (Agatías: Historias, II, 30, 3, 6-12; Keydell, p. 80; y traducción inglesa de J.D. Frendo, p. 65).

31 Cf: Ph. Hoffmann: art. cit., p. 561.

32 Ver I. Hadot: «La vie et l'oeuvre de Simplicius d'après des sources grecques et arabes», en I. Hadot (ed.): Simplicius. Sa vie, son oeuvre, sa survie. Actes du colloque international de Paris (28 sept.-1 ${ }^{\text {er }}$ oct. 1985), BerlínNueva York, 1987, p. 8; y Le problème du néoplatonisme alexandrin: Hiéroclès et Simplicius, París, 1978, p. 24.

33 Hist., II, 30, 3, 9-10 (Keydell).

34 Porfirio: Vida de Plotino, 3, 15-17 (Henry-Schwyzer).

35 Cfr. Porfirio: op. cit., 3, 21-24. 
norante y filósofo impostor que pretendía seducir a Cosroes, Uranio ${ }^{36}$. Probablemente Agatías redactó la historia de los siete filósofos con la intención de corregir la versión de Uranio ${ }^{37}$. Estos siete filósofos «auténticos» son helenos de orígenes muy diversos, pero todos ellos orientales, pues provienen de diferentes lugares de Asia Menor o de regiones de Siria y Palestina: Damascio de Siria, Simplicio de Cilicia, Eulamio (o Eulalio, como aparece en el texto de la $S u d a^{38}$ ) de Frigia, Prisciano de Lidia, Hermias y Diógenes de Fenicia, e Isidoro de Gaza.

Sin embargo, tampoco podemos afirmar con total certeza que fueran todos ellos filósofos neoplatónicos, algunos de ellos podrían ser profesores de retórica paganos. La única certeza sobre su filiación neoplatónica la tenemos con Damascio, Simplicio y Prisciano. De este último conservamos una traducción latina de un tratado, redactado quizás en persa, y dedicado al rey Cosroes: Solutiones eorum de quibus dubitavit Chosrores Persarum rex ${ }^{39}$. A. Cameron destaca la simpatía de Agatías por los siete filósofos ${ }^{40}$. Sin embargo, I. Hadot no se muestra tan segura, y considera que Agatías ridiculiza a cada uno de los personajes de este relato, especialmente a Cosroes y Uranio, sin excluir a los siete sabios ${ }^{41}$.

La decisión de exiliarse a Persia no carece de un fundamento realista. La escuela nestoriana de Nísibis, en otro tiempo radicada en Edesa (Siria), se instala en Persia, y obtiene de los reyes persas una libertad de pensamiento que contrasta con la intolerancia bizantina. En la escuela de Nísibis se estudia la cultura griega y el siriaco. Durante un corto período de tiempo, Persia reúne unas condiciones favorables para atraer a los filósofos, basadas fundamentalmente en la tolerancia religiosa y la posibilidad de transmitir la filosofía griega.

Pero, ¿cuándo se produce la huida de Atenas? Cosroes sube al trono el 13 de septiembre de 531, por tanto, dos años después del edicto de Justiniano, ¿ocupaba el trono cuando los filósofos neoplatónicos llegaron a Persia?, o ¿la acogida de los exiliados se produce con anterioridad, en una fecha próxima a la orden de clausura? La fecha del exilio que sugiere Cameron sería posterior. Pero, el testimonio de Agatías nos indica que los filósofos no se vieron atraídos por la gloria del rey Cosroes, sino por las costumbres de los persas. Proponer una fecha tan tardía no se sostiene a partir del texto de Agatías, y, al mismo tiempo, retarda en exceso la aplicación del edicto de Justiniano. No obstante, mostramos nuestra cautela a la hora de precisar la fecha del exilio a Persia de los siete filósofos, ya que Agatías, único testimonio del que disponemos, no aporta más datos relevantes.

El rey Cosroes, contemporáneo de dos emperadores bizantinos, Justiniano (527-565) y Justino II (565-578), encarna el modelo del rey justo transmitido por la tradición árabo-persa y la historiografía siríaca nestoriana ${ }^{42}$. Al final del mundo antiguo, Cosroes constituye el único so-

36 Uranio, médico y filossofo aristotélico de origen palestino, forma parte del séquito del embajador Areobindo, poco después de la firma de los acuerdos de paz de 532. Ataviado como maestro de elocuencia, logra impresionar a Cosroes, ante quien diserta sobre «la generación y la naturaleza» (cfr. Hist., II, 29, 6, 1-11, 30)

37 Cfr. Averil Cameron: «The point of is attack on Uranius is not that he indulges in theological speculation as such, but that he is incapable of it» (op. cit., p. 129).

38 Ver n. 5.

39 Prisciano de Lidia: Solutiones eorum de quibus dubitavit. Chosores Persarum rex, edición crítica, I. Bywater, C.A.G., Supplementum Aristotelicum, I, 2, Berlín, 1886, pp. 41-104.. Sobre este tratado, véase M. Tardieu: «Sabiens coraniques e ‘Sabiens' de Harran», Journal Asiatique, 274, 1986, pp. 23-24, e I. Hadot: Le problème..., p. 240. C. Steel sostiene que este comentario pertenece a Simplicio (Priscian. On Theophrastus on Sense-Perception, translated by P. Huby, with «Simplicius» On Aristotle. On the Soul 2.5-12, translated by C. Steel, in collaboration with J.O. Urmson, notes by P. Lautner, Londres, pp. 105-140).

40 Averil Cameron: op. cit., p. 101.

41 Cf. I. Hadot: Le problème..., p. 24, n. 35, y «La vie et l'oeuvre..»., pp. 8-9.

42 Sobre Cosroes, ver la entrada de M. Tardieu: «Chosroès», en R. Goulet (ed.): D.Ph.An. II., pp. 309-318; A. Christensen: L'Iran sous les Sassanides [1936], Copenhague-París, 1942, pp. 363-440; y G. Fernández: «El rey persa Khusro I Anosharvan y la filosofía ante la crisis del año 529 d.C. Un nuevo episodio de la penetración de la cultura griega en Irán», Gerión, 5, 1987, pp. 171-181. 
berano «bárbaro», interesado por la filosofía griega, y el único que frecuenta a los filósofos. En el Imperio Romano parecería posible trazar un paralelismo con las figuras de otros dos monarcas, Marco Aurelio y Juliano. Sin embargo, los pasajes de la Biblioteca de Focio y de la Suda critican a este soberano por «hablar un lenguaje tosco y enemigo de las Musas» ${ }^{43}$

La imagen de monarca tolerante, protector de filósofos y científicos de todos los orígenes y confesiones, le hace gozar de un inmenso prestigio entre los persas y los romanos, pero especialmente entre aquellos paganos opuestos a Justiniano. Su celo por las letras le llevó a encargar una traducción al persa de las obras de Platón y de Aristóteles. Si bien, un cierto tono irónico se desprende del relato de Agatías: el rey, al final de su formación autodidacta, se ha convertido en un «sabio» (бoфós), «muy superior a los filósofos de antaño en lo que concierne a discernir principios y causas de todas las artes y las ciencias» ${ }^{44}$. Para Agatías es imposible que un monarca «bárbaro» como Cosroes acceda a la paideia griega. Pero, generalmente, el acceso a Platón y Aristóteles lo realiza por el intermediario de introducciones a la lectura de sus obras o epitomai, tratados o manuales de iniciación a la filosofía griega que los filósofos paganos dedicaban al rey en señal de agradecimiento por su acogida. La obra citada de Prisciano, Solutiones eorum de quibus dubitavit Chosrores Persarum rex, compuesta en torno al año 532 , consiste en una introducción a la filosofía en forma de nueve exposiciones de psicología y de física: la naturaleza del alma (1), la vigilia y los sueños (2-3), los climas y las estaciones (4), los pronósticos y los remedios (5), el régimen de las mareas del mar Rojo (6), los fenómenos atmosféricos de gravedad (7), la transformación de los vegetales y los animales según los diferentes países (8) y los reptiles (9).

Al comienzo del relato, Agatías señala que los siete filósofos paganos tenían una imagen positiva de Cosroes. Una imagen que coincide, por tanto, con la que recibimos transmitida por la historiografía árabo-persa. De este modo, los filósofos exiliados estimaban que «el régimen político de los persas era mucho mejor» ${ }^{45}$ que el de Justiniano, al mismo tiempo, que «estaban convencidos de que sus dirigentes eran completamente justos ${ }^{46}$. Esta imagen del soberano se corresponde con la descripción que Platón presenta en la República del filósofo-rey ${ }^{47}$. Sin embargo, a continuación, Agatías trata de refutar este tipo de exégesis aplicada a un monarca oriental como Cosroes. En el transcurso de una conversación con el rey, descubrieron que Cosroes «se vanagloriaba sin duda de ser filósofo, pero no entendía ninguna de las doctrinas más profundas ${ }^{48}$. Decepcionados, los filósofos «se despidieron de la hospitalidad del bárbaro», y regresaron «lo más rápido posible» a su país ${ }^{49}$, pero tras obtener antes del rey la seguridad de su protección, como testimonia una cláusula del acuerdo de paz, firmado entre los persas y los romanos en 532, que, a su regreso, les garantizaba poder «vivir sin temor, el resto de su vida, según su elección» 50 .

Esta protección que otorga Cosroes a los filósofos paganos (que no eran sus súbditos, pero que se oponían al régimen de Justiniano) pone de manifiesto la habilidad del soberano persa en política exterior. La imagen de príncipe justo y moderado se fortalecía, al mismo tiempo que marcaba una clara oposición al emperador bizantino. «Como se elogiaba a los persas en todas partes, pensaron que podrían construir en el país de acogida el ideal platónico del filósoforey $»^{51}$. Entre ellos predominaba la concepción de un rey que gobernaba a unos súbditos «mo-

43 Hist., II, 28, copiado en Suda X, 418, t. IV, p. 816, 9-36 (Adler).

44 Hist., II, 28, 6, 28-29.

45 Hist., II, 30, 3, 12.

46 Hist., II, 30, 3, 14.

47 Cfr. Platón: República, V, 473d, en conexión con Hist., II, 30, 3, 14-15.

48 Hist., II, 31, 1, 5-6.

49 Cfr. Hist., II, 31, 1, 4-8.

50 Hist., II, 31, 4, 17-18.

51 Hist., II, 30, 3, 14-15. 
derados y honestos». Creían que en el régimen de Cosroes no prosperaban ni ladrones ni pillos, hasta el punto de que si alguien abandonara en un lugar un bien preciado, ninguno de los transeúntes lo arrebataría, sino que permanecería allí hasta la vuelta de su propietario. Por todo esto, señala Agatías, pero especialmente por el contraste respecto a la situación vivida en Atenas tras las medidas de Justiniano («por la prohibición que les dirigió, en ese momento, de vivir libremente como ciudadanos»), los siete filósofos se mostraban disconformes con el «orden establecido», lo que les llevó a emprender el camino del exilio, «a lugares extraños y salvajes», con la intención de pasar allí el resto de sus vidas ${ }^{52}$.

En contraste con el Imperio cristiano, con el exilio renace el ideal platónico de una república justa. Sin embargo, lo mismo que Platón en Sicilia, los siete filósofos neoplatónicos se toparon en Persia con una realidad decepcionante. Descubrieron que la manera de vivir persa les obligaba a abandonar pronto el ideal del filósofo-rey: corrupción, orgullo, abundancia de ladrones y malhechores, injusticias, abuso de los poderosos sobre los débiles..., pero, especialmente, un hecho en el que Agatías insiste: pese a que estaba permitida la poligamia, se seguían cometiendo adulterios ${ }^{53}$.

Por todo ello, «los filósofos vivían una situación insoportable y se reprochaban a ellos mismos el exilio» ${ }^{54}$. Aunque Cosroes deseaba que permanecieran, Damascio y sus seguidores regresaron al interior de las fronteras del Imperio Bizantino. En 532 se firmó un tratado de paz entre el rey persa y Justiniano, donde se incluía una cláusula que garantizaba la libertad de conciencia de los filósofos paganos.

Sin embargo, sacaron provecho de su exilio, y no en algo pequeño y despreciable, sino en que pueden pasar el resto de su vida del modo más agradable y placentero. En efecto, como en esta época los romanos y los persas concertaron tratados y convenciones, hubo una parte del texto de esos tratados que especifica que estos hombres, al regresar a sus propios países, puedan vivir sin temor el resto de su vida y según su propia elección, sin verse obligados a pensar cualquier cosa que pudiera estar en contradicción con sus opiniones o a cambiar las creencias de sus antepasados ${ }^{55}$.

Agatías nos transmite una anécdota extraordinaria sucedida a su regreso del exilio ${ }^{56}$ : los filósofos descubrieron sin enterrar el cadáver de un persa, hecho que consideran monstruoso, y se afanaron en darle sepultura. La noche siguiente, según Agatías, uno de los filósofos tuvo

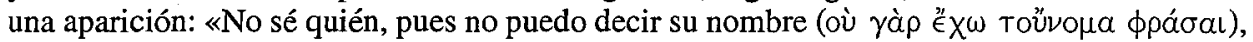
vio a un anciano con el aire grave de un filósofo, que pronunció ante él el siguiente oráculo: 'No des sepultura a aquél que no debe sepultarse, déjalo ser presa de los perros; la Tierra, madre universal, no recibe a un hombre que mancilla a su madre' ${ }^{57}$. Cuando el filósofo que tuvo la visión, cuyo nombre no precisa Agatías, contó su sueño a los otros, y regresaron al lugar en que habían enterrado el cadáver, lo encontraron «rechazado por la tierra ${ }^{58}$. En opinión de I. $\mathrm{Hadot}^{59}$, Agatías pudo haber recopilado este relato de uno de los libros de «cuentos fantásti-

52 Cfr. Hist., II, 30, 4, 21-24.

53 Cfr. Hist., II, 30, 30-31. «Persia was as full of criminals and undesirables as any other country, and what is more, Chosroes himself little better than any other barbarian» (A. Cameron: Agathias, p. 101).

54 Hist., II, 30, 7, 32-33.

55 Hist., II, 31, 3, 13-4, 19.

56 Cfr. Hist., II, 31, 5, 21-9, 17.

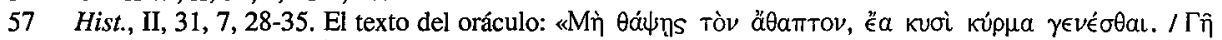

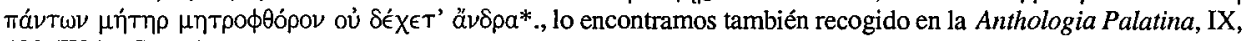
498 (Waltz-Soury).

58 Hist., II, 31, 8, 9-10.

59 Cfr. I. Hadot: Le problème..., p. 23, n. 31. 
cos» sobre Damascio, o Paradoxa, a los que Focio hace referencia ${ }^{60}$. Esta obra consta de cuatro libros: el primero titulado «Trescientos cincuenta y dos capítulos sobre ficciones extraor-

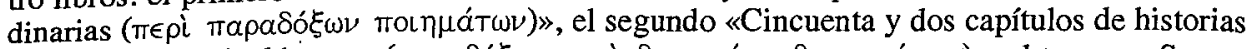
extraordinarias de démones (

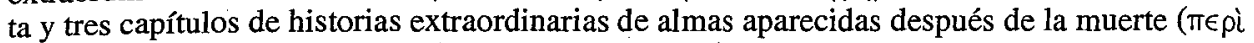

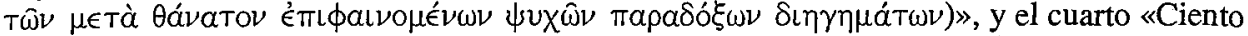

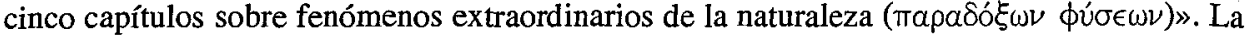
anécdota transmite, desde el punto de vista griego, el precepto zoroastrista de abandonar a los muertos en lugares especiales para que sean devorados por las bestias. El fantasma del anciano, con «aire grave de filósofo», es un zoroastrista. El filósofo que regresa del exilio ve al espíritu del difunto, mientras su cuerpo es devorado por lo perros y las rapaces, evitando que la tierra entre en contacto con su cadáver.

Pero, ¿que sucede después del regreso al territorio bizantino?; ¿a dónde se dirigieron Damascio y sus acompañantes tras sufrir una enorme decepción de su exilio en Persia?; ¿se produjo una diáspora o, más bien, un regreso a sus tierras de origen? El texto de Agatías, única fuente disponible para reconstruir el exilio de los filósofos paganos, no nos informa nada sobre este punto. Alan Cameron ${ }^{61}$, J. Glucker ${ }^{62}$, J.P. Lynch ${ }^{63}$, N.G. Wilson ${ }^{64}$ y G. Hernández ${ }^{65}$ consideran que regresaron a Atenas. L.G. Westerink no abandona del todo la hipótesis de un posible regreso a Atenas de los filósofos neoplatónicos ${ }^{66}$. Según Glucker, Simplicio escribió sus comentarios en Atenas, después del exilio persa, como investigador exento de docencia. Sin embargo, A. Frantz, a partir de datos arqueológicos e históricos, sostiene que los edificios que ocupaban las escuelas filosóficas atenienses fueron abandonados en torno al año $529^{67}$. Pero, antes de su huida, ocultaron las esculturas paganas en un lugar seguro, como atestiguan las excavaciones realizadas por los arqueólogos americanos. Para H. Blumenthal ${ }^{68}$, I. Hadot $^{69}$ y Ph. Hoffmann $^{70}$ la escuela neoplatónica de Atenas y, con ella, la enseñanza de la filosofía, se extinguieron a partir de la aplicación del edicto de Justiniano.

Por el contrario, Alan Cameron sostiene que la Academia (identificada con la escuela neoplatónica de Atenas) sobrevive al edicto de Justiniano que ordenaba su clausura, y que la confiscación de los bienes no fue efectuada hasta finales del s. VI ${ }^{71}$. Según este autor, los «salarios» de los diádocos continuaron pagándose y la biblioteca permaneció abierta. Los comentarios de Simplicio, propone Cameron, fueron escritos en Atenas, empleando el material bibliográfico de la Academia.

El debate sobre la continuidad o cierre definitivo de la escuela neoplatónica de Atenas parte del análisis de un pasaje del Comentario al Primer Alcibíades de Olimpiodoro (circ. 560): «Quizás Platón no admitía ningún salario, porque era un hombre rico, por ello, las rentas (T⿳亠口冋 $\delta\llcorner a \delta \circ \chi\llcorner\kappa a ́)$ se han preservado hasta el presente, y todo ello a pesar de las múltiples confisca-

60 Cfr. Focio: Biblioteca, cod. 230, t. II, p. 104 (Henry).

61 Cfr. A. Cameron: «The last days..»., pp. 7-29; y «La fin de l'A cadémie..»., pp. 288-290.

62 Cfr. J. Glucker: op. cit., pp. 322-329.

63 Cfr. J.P. Lynch: Aristotle School: a study of a Greek educational institution, Berkeley-Los Ángeles-Londres, 1972, pp. 167-168..

64 Cfr. N.G. Wilson: Scholars of Byzantium, Londres, 1983, pp. 37-38.

65 Cfr. G. Hernández: «Justiniano y la clausura..»., pp. 29-30.

66 Cfr. L.G. Westerink, en L.G. Westerink, J. Trouillard y A.Ph. Segonds (eds.): op. cit., pp. xvii-xxi.

67 Cfr. A. Frantz: «Pagan philosophers in Christian Athens», Proceedings of the American Philosophical Society, 119, 1975, pp. 32-38; y The Athenian Agora..., pp. 84-92.

68 Cfr. H. Blumenthal: art. cit., pp. 369-385.

69 Cfr. I. Hadot: «Le problème du néoplatonisme..»., pp. 26-27.

70 Cfr. Ph. Hoffmann: art. cit., p. 548.

71 Cfr. A. Cameron: «The last days..»., pp. 26-29. 
ciones que se producen» ${ }^{72}$. Aquí la expresión tà $\delta \iota \alpha \delta o \chi \iota k a ́$ alude no al «salario» del diádoco o de los profesores, sino a las «rentas» 0 «posesiones» de la escuela. Si lo interpretamos de este modo, parece no haber una razón suficiente para sostener la continuidad de la escuela de Atenas después del exilio de los siete filósofos. Las «posesiones» continuaron todavía unos años, pero no así los «salarios» de los profesores. La única actividad que se admitiría sería un trabajo puro de investigación, exento de cualquier clase de docencia.

Pero el problema se nos plantea a la hora de determinar el lugar de trabajo de Simplicio después del exilio. En principio parece que caben tres posibilidades: ¿regresó a Atenas, como pretenden Glucker y Cameron, y en esta ciudad compuso sus comentarios a Aristóteles?, ¿se retiró a Alejandría, y accedió a su rica biblioteca?, o bien, ¿pudo más bien escoger alguna otra ciudad de Asia Menor? Si fuera Atenas el lugar donde se instala, su actividad estaría consagrada a la labor de investigador puro, y no a la de docente. La hipótesis alejandrina se tambalea desde el momento en que en su Comentario al Sobre el cielo de Aristóteles, escrito para refutar los tratados de Juan Filópono De aeternitate mundi contra Proclum y De aeternitate mundi contra Aristotelem, señala que no ha conocido a su autor en persona ${ }^{73}$. Sin embargo, sabemos que Juan Filópono residía en Alejandría los años posteriores al exilio de Simplicio ${ }^{74}$. Un tercer posible destino se nos presenta: una ciudad griega de Asia Menor. Hemos de tener en cuenta el origen de todos ellos. Simplicio provenía de Asia Menor, por lo que podría aún conservar familia o bienes en Cilicia. Pero nos resulta difícil pensar que en esta ciudad haya podido elaborar sus comentarios ${ }^{75}$, todos ellos redactados después del exilio, sin poder disponer de una valiosa biblioteca.

Por tanto, parece que, llegados a este punto, ninguna de las tres posibilidades arriba mencionadas nos satisface del todo. Si descartamos los destinos de Atenas, de Alejandría y de una ciudad de Asia Menor, ¿dónde pudieron instalarse Damascio, Simplicio y el resto de filósofos paganos a su regreso del exilio persa? Las recientes investigaciones de $M$. Tardieu demuestran que fue en Harrân, una ciudad situada en el Imperio Bizantino, pero en las proximidades de Persia, un cruce de caminos entre el mundo helenístico, árabe y siríaco ${ }^{76}$. La tesis de Tardieu se basa en el análisis de la crítica que Simplicio dirige a la doctrina cosmológica maniquea en su Comentario al Manual de Epicteto. Para elaborar su refutación, Simplicio contacta directamente con un interlocutor maniqueo que sólo podía hallarse en Harrân. En esta ciudad, los filósofos podrían utilizar la lengua griega fuera de su comunidad, además del arameo, hablado al menos por cuatro de ellos. Tres siglos después de la llegada de los neoplatónicos, en torno a 901, Tâbit b. Qurra, procedente de Harrân, funda en Bagdad una escuela que pronto se convierte en un importante centro de recepción y difusión de la ciencia y de la filosofía griegas entre los árabes ${ }^{77}$.

72 Olimpiodoro: Comentario al Primer Alcibiades, 141, 1-3 (Westerink). Sobre la datación de este tratado, J.P. Lynch: op. cit., p. 167.

73 Cfr. Simplicio: Comentario al Sobre el cielo de Aristóteles (In De caelo), p. 26, 17-24 (Heiberg).

74 Cfr. H.D. Saffrey: «Le chrétien Jean Philopon et la survivance de l'Ecole d'Alexandrie au VI' siècle», Revue des Études Grecques, 67, 1954, pp. 396-408.

75 Los tres comentarios a Aristóteles, en orden cronológico, al Sobre el cielo, a la Física y a las Categorías, fueron escritos después de 529 (cfr. I. Hadot: «La vie et l'oeuvre..»., p. 28).

76 Cfr. M. Tardieu: «Sabiens coraniques et 'Sabiens» de Harrân», Journal asiatique, 274, 1986, pp. 1-44; «Les calendriers en usage à Harrân d'après les sources arabes et le commentaire de Simplicius à la Physique d'Aristote», en I. Hadot (ed.): Simplicius. Sa vie, son oeuvre, sa survie, pp. 40-57; y Les paysages reliques. Routes et haltes syriennes d'Isidore à Simplicius, Lovaina-París, 1991, pp. 71-102

77 Tardieu, basándose en fuentes árabes ( $\left.a l-M a s^{\prime} \hat{u} d \hat{\imath}\right)$, señala que una escuela neoplatónica perdura en Harrân hasta el s. X. En efecto, la literatura árabe refleja datos de la biografía de Simplicio que no figuran en los escritos bizantinos. Así, en el Fihrist de al-Nadîm (s. X), Simplicio es considerado un matemático de prestigio, autor de un Comentario a los Elementos de Euclides. Al-Nayrîzî, en el s. IX, utiliza una traducción árabe del primer libro de este comentario de Simplicio (cfr. I. Hadot: Simplicius, p. xx, basado en la tesis de A.I. Sabra: «Simplicius's proofs of Euclid's parallels postulate», Journal of the Warburg and Courtauld Institutes, 32, 1969, pp. 1-24). 
Tardieu aporta otra prueba aún más decisiva: en los comentarios a Aristóteles, Simplicio alude a una embarcación, semejante a una balsa, que flota sobre odres hinchados ${ }^{78}$. El propio Simplicio afirma que «ha experimentado» ${ }^{79}$ este tipo de embarcación en su descenso del río Aboras (Hâbûr), afluente del Éufrates. La abundante documentación que Tardieu aporta basta para demostrar que Simplicio, después de instalarse en Harrân, desciende el río Aboras, cuando regresaba de una peregrinación a las fuentes sagradas del río ${ }^{80}$.

Por tanto, casi con toda probabilidad, los cinco comentarios íntegros de Simplicio que han llegado hasta nosotros fueron redactados en Harrân, con posterioridad al año 532, fecha del acuerdo de paz firmado entre Cosroes y Justiniano: el comentario al Manual de Epicteto (inscrito en la restauración del cursus de la escuela de Atenas, ya que la iniciación neoplatónica exigía una formación ética como etapa previa a una formación intelectual), y los comentarios al Sobre el cielo, a la Física, al Sobre el alma (este último de dudosa autenticidad, probablemente obra de Prisciano) y a las Categorias de Aristóteles.

Por lo que se refiere al resto de los compañeros del exilio, desconocemos su destino a su regreso de Persia. Sólo disponemos de un dato: el epitafio del esclavo Zósimo. En la Anthologia Palatina hallamos un epigrama escrito en honor de un esclavo difunto, llamado Zósimo, compuesto en Siria en 538: «Zósimo, que antes sólo era esclavo de cuerpo, ahora ha ganado también para su cuerpo la libertad» ${ }^{81}$. En Emesa, ciudad próxima a Damasco (lugar de nacimiento de Damascio) se descubrió a principios del s. XX un epitafio, inscrito en una losa basáltica, que contiene el mismo epigrama de la Anthologia Palatina ${ }^{82}$. La concordancia de la tradición manuscrita con este testimonio epigráfico pone de manifiesto la presencia en Siria de Damascio después del exilio persa, concretamente en torno al año 538, cuando el anciano «diádoco» contaba entre 75 y 80 años.

\section{EL MALESTAR DE LOS TIEMPOS PRESENTES}

La Vida de Isidoro de Damascio constituye no sólo una biografía de su maestro y antecesor como diácono, sino también un recorrido por la historia de la filosofía en la escuela neoplatónica desde finales del s. IV. En un pasaje de la Vida de Isidoro, comentado por H.D. Saffrey $^{83}$, Damascio establece una correspondencia entre las partes del alma y los regímenes políticos $^{84}$. El antecedente se remonta a la República, IV, de Platón, que Proclo analiza en el

78 Cfr. Simplicio: In De caelo, p. 525, 10-13 (Heiberg); e In Phys., p. 684, 35-685, 3 (Diels).

79 In De caelo, p. 125, 13.

80 El río Aboras transcurre a unos $40 \mathrm{~km}$. al este de Harrân. La peregrinación de Simplicio a sus fuentes sagradas entronca con la tradición viajera neoplatónica desde Plotino, quien se une a la expedición de Gordiano contra los persas, pasando por Jámblico, quien se dirige con sus discípulos a las fuentes de Gadara, hasta el periplo de Isidoro y Damascio por el sur de Siria. El siguiente pasaje de la Vida de Isidoro recoge la significación del viaje en el neoplatonismo, que pone en ridículo las costumbres turísticas de sus contemporáneos: «[Damascio] se mostraba apasionado por los viajes al extranjero: pero no por el viaje inútil y cómodo cuyo fin es quedarse boquiabierto ante los edificios humanos, el tamaño y la belleza de las ciudades; al contrario, si había oído decir que existía, en alguna parte, algo asombroso o sagrado, secreto o célebre, quería ser el testigo directo del prodigio» (Vit. Isid., fr. 38 (=Focio: Biblioteca, 239), p. 35, 14-17 Zintzen). Sobre las fuentes del río Aboras (Habûr), véase M. Tardieu: Les paysages..., pp. 103-135.

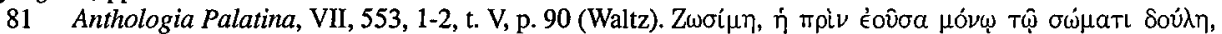

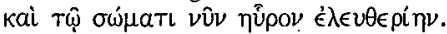

82 Cfr. L. Jalabert y R. Mouterde: Inscriptions grecques et latines de la Syrie, t. V, Paris, 1959, p. 155, $\mathrm{n}^{\circ} 2336$. La inscripción es fechada en torno al año 538.

83 Cf. H.D. Saffrey: «Le thème du malheur des temps chez les derniers philosophes néoplatoniciens», en $A A$. VV.: $\Sigma О Ф I H \Sigma$ MAIHTOPE $\Sigma$, 'Chercheurs de sagesse». Hommage à Jean Pépin, París, 1992, pp. 424-426 (=id.: H.D. Saffrey (ed.): Le Néoplatonisme après Plotin, París, 2000, pp. 210-212).

84 Focio recoge en el Codex 242 de su Biblioteca dos fragmentos, el 22 y el 238, además de la Suda. En la edición de Zintzen correspoden, respectivamente, a los fragmentos 30 y $30 \mathrm{a}$. 
comentario que dedica a este diálogo ${ }^{85}$. Sin embargo, este tema, que Proclo aborda de un modo neutral, Damascio lo proyecta en forma de crítica al régimen político del Imperio Bizantino de su tiempo.

Como hay tres tipos de almas, hay también tres géneros de regímenes políticos: sin duda, cada uno presenta los tres tipos [de alma], pero recibe su forma y su nombre del tipo que predomina.

Por la razón $(\lambda o ́ \gamma(\omega)$ es gobernado el régimen político que es como la vida en el tiempo de Crono (ó ẃs étì Kpóvou Bíos), o bien el que se llama la edad de oro ( $\chi \rho v \sigma \hat{\eta} \gamma \in \nu \in-$

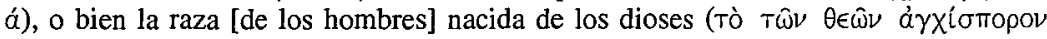
yévos), como, en forma de mito, los poetas, sentados en el trípode de las Musas, elogian. Por lo irascible $(\theta v \mu \hat{\omega})$ es gobernado el régimen político que se precipita a las guerras y los combates y que, en general, lucha por los primeros puestos y por la gloria, como hemos oído decir que ha sucedido a lo largo de todas las ocasiones en la historia ( $\tau \grave{\eta} \nu$ éti

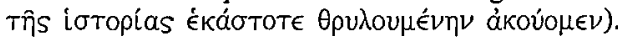

Por lo concupiscible (Ėmıvuíạ) es gobernado el régimen político que se propaga por todas partes, corrompido por un goce intemperante, que sólo tiene los pensamientos bajos e indignos de un hombre, que es inseparable de la cobardía, que se revuelca en cualquier clase de fango, ávido de riquezas, mezquino, que quiere con firmeza una vida de escla-

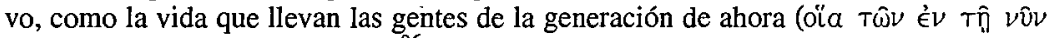

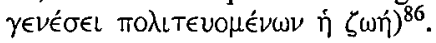

En este fragmento, y en el paralelo de la $S u d a^{87}$, Damascio distingue tres edades. El tercer régimen, gobernado por lo concupiscible, corresponde al régimen del Imperio Bizantino. No obstante, vayamos paso a paso y analicemos cada una de las tres edades:

1) La edad mítica aparece «gobernada por la razón», la vida «en el tiempo de Crono» (poemas órficos), o la «edad de oro» (Hesíodo), la «raza [de los hombres] nacida de los dioses» (Esquilo). Los neoplatónicos atenienses se remontan a esta edad mítica, cuando tratan de armonizar las antiguas tradiciones teológicas del helenismo.

2) La edad de los grandes hombres políticos, sobre la cual los historiados relatan sus hazañas, está «gobernada por lo irascible», y coincide en la historia con el tiempo «ya pasado» en que las ciudades se enfrentaban en guerras o competiciones con el objetivo de alcanzar los primeros puestos y, con ellos, la gloria.

3) La edad de los emperadores cristianos, la época en la que vivió Damascio, está gobernada por lo concupiscible. Se trata de una época de esclavitud, semejante a un «cuerpo paralizado», incapaz de moverse. A medida que el cristianismo se convierte en la religión dominante en el Imperio Romano, especialmente una vez que adquiere la condición de religión de Estado en el Imperio Bizantino, los emperadores se apartan

85 Proclo: Comentario a la República de Platón, 1, p. 207, 14-231, 3 (Kroll).

86 Focio: Biblioteca, t. VI, pp. 4748 (Henry). Frag. 238 (Frag. 30 Zintzen).

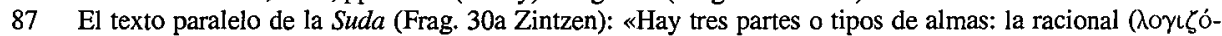

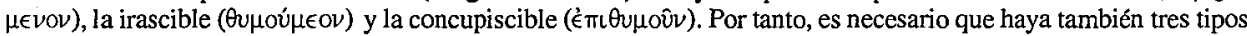
de regímenes políticos, y que cada uno de ellos presente los tres tipos de alma, pero principalmente configurado por el único tipo dominante: Y el primer régimen político procede según la razón (кatà $\lambda o ́$ ovo): podríamos llamarlo la

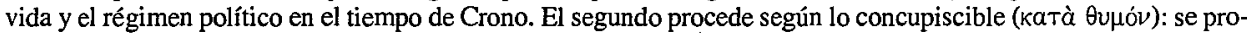
paga por todas partes, está corrompido por un gozo intemperante, sólo tiene pensamientos bajos e indignos de un hombre, es inseparable de la cobardía y se vuelca en cualquier clase de fango, es ávido de riquezas, mezquino, no lleva a cabo nada estimable ni libre, es digno de un esclavo y vil, limita siempre su felicidad a su vientre y a su sexo y no muestra nunca una noble ira; es como un cuerpo paralizado, actuando de algún modo irritado e incapaz de moverse aún. De una manera más miserable aún Damascio representaba la vida de los hombres que hoy llevan su existencia en el mundo de la generación». 
progresivamente de la antigua religión pagana, e incluso intentan erradicarla. Desde Constantino (306-324), Teodosio (37-393) y sobre todo Justiniano (527-565), la legislación se vuelve cada vez más represiva ${ }^{88}$.

La prohibición de los ritos, y la destrucción o transformación de los santuarios paganos, llevó a los filósofos neoplatónicos a considerarse los últimos exponentes de las antiguas tradiciones paganas ${ }^{89}$. En Atenas, desde 430 , la práctica religiosa pagana era ya clandestina. Las palabras de Damascio, especialmente en el texto que nos transmite la Suda, manifiestan esa «nostalgia» por los tiempos pasados frente a la «desgracia» de los tiempos presentes.

Podemos pensar, con R. von Haehling ${ }^{90}$, que la resistencia de los filósofos neoplatónicos en Occidente no se había limitado exclusivamente al aspecto «académico», como defiende A.H.M. Jones ${ }^{91}$. Damascio se muestra especialmente duro con los dirigentes políticos de su tiempo. Para describir el malestar de su momento histórico, acude a términos y expresiones platónicas extraídas del gobierno corrupto de la República: goce intemperante, pensamientos bajos, ruindad, avaricia, mezquindad y esclavitud.

\section{LAS CAUSAS DEL EXILIO Y EL CIERRE DE LA ESCUELA NEOPLATÓNICA DE ATENAS}

El objetivo último de los filósofos neoplatónicos radica en una asimilación a Dios, para lo que se requiere una actitud ascética, una huida y un abandono espiritual del mundo que coincide con el «exilio». Ahora bien, la vida política, en vez de ser la antítesis de la asimilación del hombre a la divinidad, constituye un contexto y una etapa indispensable. En el capítulo segundo de la Enéada $\mathrm{I}^{92}$, Plotino nos recuerda, por medio de una cita del Teeteto ${ }^{93}$, el principal objetivo del proyecto del filósofo neoplatónico que consiste en la huida del mundo y la asimilación a lo divino. Sin embargo, esta «asimilación» a lo divino, o «divinización» ${ }^{94}$, se consigue por medio de la virtud y, ante todo, por el primer eslabón en la escala de las virtudes, que Plotino identifica con las «virtudes políticas», siguiendo la definición platónica de República IV: prudencia, valentía, moderación y justicia ${ }^{95}$. Por tanto, desde la perspectiva neoplatónica, la vida política representa la primera etapa del proceso de divinización del hombre. La asimilación a Dios exigía al filósofo neoplatónico dedicarse a la contemplación y ejercer, al mismo tiempo, responsabilidades políticas. Este proyecto neoplatónico sintoniza con la explicación de las causas del «exilio» de Damascio y el cierre de la escuela neoplatónica de Atenas. El régimen político de Justiniano, opuesto al modelo trascendente de la ciudad inteligible platónica, no ofrecía el contexto político adecuado en el que alcanzar la asimilación del hombre a la divinidad.

Pero también en Simplicio se perciben las consecuencias nefastas de la prohibición de la enseñanza de la filosofía. En el capítulo catorce de su Comentario al Manual de Epicteto nos

88 Ver G. W. Bowersock: «Paganism and Greek Culture», Hellenism in Late Antiquity, 1990, pp. 1-30.

89 Véase, A. Frantz: «From Paganism to Christianity in the temples of Athens», Dumbarton Oaks Papers, 19, 1965, pp. 187-205; y «Pagan philosophers in Christian Athens..»., pp. 29-38.

90 Cfr. R. von Haehling: «Damascius und die heidnische Opposition im 5. Jahrhundert nach Christus», Jahrbuch für Antike und Christentum, 23, 1980, pp. 82-99.

91 Cfr. A.H.M. Jones: «The social background of the struggle between Paganism and Chrisitanity», en A. Momigliano (ed.): The conflict between Paganism and Christianity in the fourth Century, Oxford, 1963, pp. 17-37.

92 Cf. Plotino: Enéada I, 2 [19] 1, 2-4.

93 Platón: Teeteto, 176 a-b.

94 Cfr. D. J. O’Meara: «Vie politique et divinisation dans la philosophie néoplatonicienne», en AA. VV.: $\Sigma O$ $\Phi I H \Sigma$ MAIHTOPE $\Sigma . . .$, p. 502.

95 Cf. Platón: República, IV, 1, 16-26. 
habla de «la destrucción de la cultura y de la filosofía, de toda virtud y amistad, y de toda confianza mutua» ${ }^{96}$. Como se niega a los filósofos paganos la posibilidad de transmitir las doctrinas de la filosofía platónica, desaparece también cualquier clase de virtud y de amistad, existentes en una comunidad de maestro-discípulo, basadas en una "confianza mutua». Finalmente, Simplicio se muestra satisfecho de haber podido comentar el Manual del filósofo estoico en un tiempo dominado por una atmósfera tiránica. La política que el emperador Justiniano dirige contra los filósofos no-cristianos les obligaba a la práctica clandestina de la religión pagana. Simplicio se refiere a «las violencias tiránicas» ${ }^{97}$, en clara alusión a las leyes de Justiniano que prohibían todo tipo de culto a los dioses paganos, e incluso obligaban al bautismo cristiano, lo que condenaba a los paganos a la práctica de la impiedad ${ }^{98}$. A partir de 527 , los templos se destruyeron o se transformaron en iglesias cristianas, al mismo tiempo que el culto desaparecía de la vida pública y la enseñanza era vetada a los profesores paganos. Nos situamos, pues, justo dos años antes del cierre de la escuela neoplatónica de Atenas por el edicto de Justiniano de 529. Dos caminos se imponían entonces a los profesores neoplatónicos: la conversión por el bautismo, y la consecuente renuncia al paganismo, o el exilio, llevándose con ellos las prácticas religiosas al país de acogida. Este segundo camino fue el que emprendieron los profesores de la escuela neoplatónica de Atenas ${ }^{99}$. Damascio, Simplicio y sus seguidores más inmediatos de la siguiente generación constituyen los últimos representantes de los filósofos paganos, una especie en grave peligro de extinción a partir de la época de Justiniano.

José M. Zamora

Departamento de Filosofía

Facultad de Filosofía y Letras

Universidad Autónoma de Madrid

28049 Madrid

E-mail: jm.zamora@uam.es

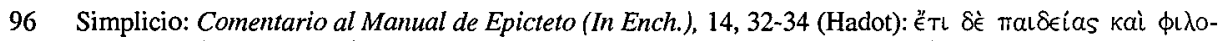

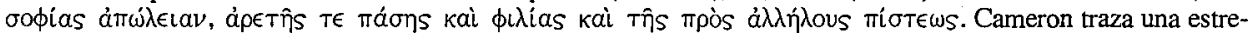
cha conexión entre las Historias de Agatías y el In Ench. de Simplicio. Si bien, la fecha de composición de este último es al menos tres años anterior al edicto de Justiniano.

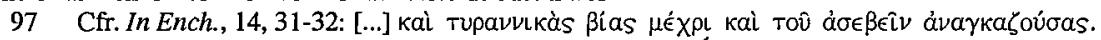

98 Ver I. Hadot: Simplicius. Commentaire sur le Manuel d'Épictète, Chapitres I-XXIX, París, 2001, p. 163, n. 2-3, donde interpreta el pasaje anteriormente citado.

99 Cfr. P. Chuvin: Chronique des derniers païens. La disparition du paganisme dans l'Empire Romain, du règne de Constantin à celui de Justinien, París, 1990. 